\title{
Variability of Total Polyphenol Contents in Ground Coffee Products and Their Antioxidant Capacities through Different Reaction Mechanisms
}

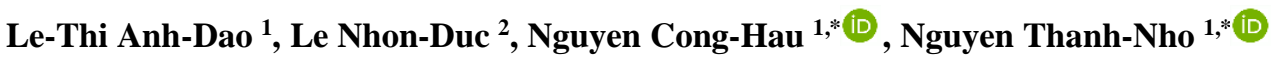 \\ 1 Faculty of Environmental and Food Engineering, Nguyen Tat Thanh University, Ho Chi Minh City, Vietnam; \\ ltadao@ntt.edu.vn (L.T A.D); nchau@ntt.edu.vn (N.C.H); ntnho@ntt.edu.vn (N.T.N); \\ 2 Warrantek Joint Stock Company-Testing Center, Can Tho City, Vietnam; nhonducle@gmail.com (L.N.D); \\ * Correspondence: nchau@ntt.edu.vn (N.C.H); ntnho@ntt.edu.vn (N.T.N);
}

Scopus Author ID 57191825637

Received: 10.08.2021; Revised: 18.09.2021; Accepted: 22.09.2021; Published: 16.10.2021

\begin{abstract}
Coffee is one of the most popular non-alcoholic drinks consumed daily by millions of individuals worldwide. It is characterized by varieties and processing, which cause changes in chemical compositions and biological activities. This study aimed to evaluate the effects of roasting degrees during the processing period (light, medium, and dark) on the total polyphenol contents (TPCs) inground coffee products of arabica, robusta, and liberica and their trolox equivalent antioxidant capacities (TEACs) through various chemical reaction mechanisms (DPPH, ABTS, FRAP, and CUPRAC). The analytical methods were conducted based on spectrophotometric principle after the microwave-assisted liquid extraction. The results of the TPCs followed the descending order of robusta (34.3-48.23 $\mathrm{mg} \mathrm{GAE} \mathrm{g}^{-1}$ ) > liberica (31.5-34.37 $\left.\mathrm{mg} \mathrm{GAE} \mathrm{g}^{-1}\right)>$ arabica (27.1-44.11 $\left.\mathrm{mg} \mathrm{GAE} \mathrm{g}^{-1}\right)$. Moreover, robusta coffee generally performed greater TEACs than liberica and arabica. Besides, the TPCs and TEACs varied regarding different roasting degrees, in which the medium roasting mostly exhibited the highest values due to the balance between the degradation of phenolic compounds and the generation of new antioxidant compounds mainly from the Maillard reactions. Strong correlations between TPCs and antioxidant capacities $\left(\mathrm{R}^{2}>0.6\right)$, indicating rich phenolic compounds played key roles in TEACs of coffee.
\end{abstract}

Keywords: coffee; arabica; robusta; liberica; TPCs; TEACs; Maillard reactions.

(c) 2021 by the authors. This article is an open-access article distributed under the terms and conditions of the Creative Commons Attribution (CC BY) license (https://creativecommons.org/licenses/by/4.0/).

\section{Introduction}

Coffee has been known as among the most common non-alcoholic beverages worldwide due to its attractive taste and health benefits for consumers. The coffee plants were initially cultivated in an Ethiopian area (Kaffa) in Africa, then brought to Yemen, Arabia, and Egypt. In these countries, coffee gradually developed and became a part of humans' daily lives [1]. There are nearly 60 nations in both tropical and subtropical regions producing coffee on a large scale. Moreover, in several countries, coffee has become the main export product [2]. When the coffee berries are ripe, they are collected, dried, roasted at various temperature ranges to obtain the desired flavor, then ground and brewed to enjoy. The two most common species of coffee berries are Coffea arabica (arabica) and Coffea canephora (robusta) [2, 3]. Coffee brews coming from $100 \%$ arabica have higher sensory quality and most acceptable to customers than robusta ones. Several publications indicated that robusta coffee performed greater antioxidant capacities than arabica $[4,5]$. 
The coffee plants have been introduced to Vietnam for a long time, then widely cultivated since 1888. At present, the coffee exported from Vietnam has appeared in many regions worldwide, such as North America, Western Europe, Eastern Europe to Australia, South Asia, North Asia. Since 1975, the areas of coffee-tree plantations have continuously increased from several to around 300000 hectares until now with high productivity. Vietnamese coffee possesses a certain potential and needs to be effectively exploited. Therefore, specific solutions should be established to maximize the quality and value of coffee. The chemical profile of coffee has been achieved great concerns due to the presence of various bioactive compounds, listed as nicotinic acid, trigonelline, quinolinic acid, tannic acid, pyrogallic acid, especially caffeine [6].

Moreover, coffee provides remarkable contents of phenolic acids belonging to the hydroxycinnamic acid family, contributing to the total polyphenol contents and antioxidant capacities [7]. However, these substances were varied regarding the differences in the processing periods, especially the temperature changes during roasting. Wang et al. (2011) showed that the phenolic contents in coffee products and their antioxidant capacities varied with roasting degrees [8], in which natural phenolic compounds might be lost while other antioxidants could be formed. The same observation was reported in various publications of Asfaw et al. (2020) [9], del Castillo et al. (2002) [10], and Opitz et al. (2014) [11]. Moreover, the study conducted by Delgado-Andrade and Morales (2005) showed that the antioxidant capacities could be increased due to the reactions during the roasting processing, particularly the Maillard reaction products [12].

Total antioxidant activity is very effective in acquiring, evaluating, and comparing general data about the antioxidant activity of different foods and beverages. Particularly, when food goes through the processing and preservation periods, the changes in the antioxidant capacities could happen. However, the antioxidant activity results need to be specifically analyzed and explained based on the chemical nature of the method used and the chemical composition of the sample analyzed. It could be seen that the antioxidant effect should always be investigated by different methods, either in vitro or in vivo. Based on the chemical nature of the in vitro, the antioxidant activity determination method can be classified into single electron transfer (SET), hydrogen atom transfer (HAT), and mixed mechanism. The methods of SET group become the most popular based on free radical capture reaction, ferric ion reducing antioxidant power (FRAP); 2,2-diphenyl-1-picrylhydrazyl radical (DPPH•) free radical scavenging/neutralization; 2,2-azinobis 3-ethylbenzthiazoline-6-sulphonic acid (ABTS $\bullet^{+}$) free radical scavenging/neutralization; cupric-reducing antioxidant capacity (CUPRAC) [1, 2]. In all of these methods mentioned, the antioxidant capacities depend on various parameters, including temperature, nature of the substances, antioxidant concentrations, and the presence of other compounds, etc. Coffee is an excellent source of antioxidants, especially the polyphenol compounds, contributing to the neutralization of free radicals and reducing power. Coffee is generally performed as a rich source of chlorogenic acids, among the strongest antioxidants with positive effects on health. However, chlorogenic acids are thermally unstable and exhibit various changes during the processing, typically the roasting.

Besides the geographical origins, the processing conditions affect the antioxidant capacities of coffee products. To the best of our knowledge, very few studies have been done on the assessment of antioxidants of coffee products in Vietnam. Therefore, this study aimed to evaluate the analytical method performance for determining total polyphenol contents (TPCs) and trolox equivalent antioxidant capacities (TEACs) by different chemical reaction 
mechanisms (DPPH, FRAP, ABTS, CUPRAC) in coffee matrices. Then, the analytical methods were applied to assess the variations in TPCs, and TEACs of coffee products belonging to different varieties and roasting degrees (light, medium, and dark). Moreover, the correlation between TPCs and TEACs was also calculated to evaluate the contribution of TPCs into TEACs for coffee products.

\section{Materials and Methods}

\subsection{Materials.}

Monohydrate gallic acid (GA, $\geq 99 \%$ purity Merck, Germany) and 6-hydroxy-2,5,7,8tetramethylchroman-2-carboxylic acid (trolox, $\geq 98 \%$ purity Merck, Germany) were used as the standards for TPCs and antioxidant capacities, respectively. For TPCs, the working standard solutions were 10.0, 20.0, 30.0, 40.0, 50.0, and $70.0 \mathrm{mg}$ gallic acid equivalent (mg

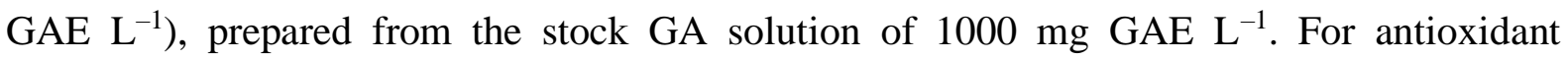
capacities, the stock trolox standard solution of $1000 \mu \mathrm{mol}$ trolox equivalent $\left(\mu \mathrm{mol} \mathrm{TE} \mathrm{L} \mathrm{L}^{-1}\right.$ ) was employed to prepare the standard working solutions of 100, 200, 300, 400, 500, 600, and $700 \mu \mathrm{mol} \mathrm{TE} \mathrm{L}{ }^{-1}$. Other reagents and solvents such as sodium carbonate, $2 \mathrm{~N}$ Folin-Ciocalteu, 2,2'-diphenyl-1-picrylhydrazyl (DPPH), 2,2'-azino-bis(3-ethylbenzthiazoline-6-sulfonic acid) (ABTS), 2,4,6-tris(2-pyridyl)-s-triazine, potassium persulfate, neocuprac, ethanol (EtOH), and methanol $(\mathrm{MeOH})$ were of analytical grade and bought from Merck (Germany). We noted that deionized water (DIW, Millipore, USA) was used throughout all the experiments.

\subsection{Sample collection and preparation of coffee extracts.}

A total number of 13 ground coffee products belonging to three varieties of arabica, robusta, and liberica with different roasting degrees (dark, medium, and light) were collected from Lam Dong Province (the Central Highland of Vietnam). During the roasting, the green coffee beans were heated at 200 to $240{ }^{\circ} \mathrm{C}$ for $10-15$ minutes depending on the required degrees of roasting, which was generally evaluated by color observation by the producers $[9,13]$.

Table 1. Sample information for the study.

\begin{tabular}{l|l|l|l} 
No. & Type of coffee & Roasting mode & Code \\
\hline 1 & & Light & Arabica-Light-1 \\
2 & Arabica & Medium & Arabica-Medium-1 \\
3 & & & Arabica-Medium-2 \\
4 & & Dark & Arabica-Dark-1 \\
5 & & Medium & Arabica-Dark-2 \\
\hline 6 & & & Robusta-Medium-1 \\
7 & & & Robusta-Dark-1 \\
8 & Robusta & Dark & Robusta-Dark-2 \\
9 & & & Robusta-Dark-3 \\
10 & & & Robusta-Dark-4 \\
11 & & Dark & Liberica-Dark-1 \\
12 & Liberica & & Liberica-Dark-2
\end{tabular}

The manufacturers thoroughly ground each kind of coffee bean product of various roasting degrees and kept it in non-permeable polypropylene/aluminum/polyethylene bags, which were hermetically sealed under a vacuum. These roasted ground and sealed coffee products were stored at $25{ }^{\circ} \mathrm{C}$ until use. The specific information of collected coffee samples is exhibited in Table 1. 
During this study, we did not have the liberica coffee products of light and medium roasting as well as the light-roasting robusta due to the limitation of experimental conditions.

The sample extraction procedure for determining TPCs and antioxidant capacities was referenced from ISO 14502-1 (2007) [14] with some modifications. Briefly, $0.2( \pm 0.001) \mathrm{g}$ of ground coffee sample endured the ultrasound-assisted solid-liquid extraction at $70{ }^{\circ} \mathrm{C}$ using the mixture of MeOH:DIW (7:3 = v/v) as the extraction solvent. The extraction was carried out in duplicate within 20 minutes (i.e., $10.00 \mathrm{~mL}$ solvent and 10 minutes for each one). All obtained extracts were collected and combined into a $50 \mathrm{~mL}$ volumetric flask, then made up to the calibration mark by MeOH:DIW (7:3 = v/v). After that, the samples were filtered through 0.45 $\mu \mathrm{m}$ PTFE membranes, appropriately diluted by DIW before further colorimetric assays and spectrophotometric measurement.

\subsection{Colorimetric assays for determining TPCs and antioxidant capacities.}

\subsubsection{Total polyphenol contents (TPCs).}

The extracts were performed a further 20-fold dilution prior to the colorimetric procedure according to the Folin-Ciocalteu method as shown in ISO 14502-1 (2007) [14] with some modifications to save the chemicals and reagents used. Shortly, $0.50 \mathrm{~mL}$ of the diluted extract was taken in a reaction tube, then $2.50 \mathrm{~mL}$ of $10 \%(\mathrm{v} / \mathrm{v})$ Folin-Ciocalteau reagent was added and shaken. The solution was let stand for around 3 to 8 minutes before adding $2.00 \mathrm{~mL}$ of $7.5 \% \mathrm{w} / \mathrm{v} \mathrm{Na}_{2} \mathrm{CO}_{3}$. The mixture was shaken gently and allowed to react for approximately 60 minutes. The absorbance was measured at $765 \mathrm{~nm}$ on Shimadzu UV-1800 UV/Visible Scanning Spectrophotometer (Japan). The TPCs in the coffee sample was performed as milligrams of gallic acid equivalents per gram ( $\mathrm{mg} \mathrm{GAE}^{-1}$ dried weight or DW).

\subsubsection{Antioxidant capacities (DPPH, ABTS, FRAP, and CUPRAC).}

The antioxidant capacities were expressed as $\mu$ mol equivalent of trolox per gram ( $\mu$ mol TE $\mathrm{g}^{-1} \mathrm{DW}$ ). In the present study, four chemical reaction mechanisms, including DPPH, ABTS, FRAP, and CUPRAC assays, were employed to assess the trolox equivalent antioxidant capacities (TEACs) among different ground coffee products. Before proceeding to the colorimetric procedures, the extracts were diluted further two times (DPPH, ABTS, and FRAP) and four times (CUPRAC).

The implementation of DPPH was referenced from Brand-Williams and SanchezMareno $[15,16]$. Briefly, $100 \mu \mathrm{L}$ of the diluted sample was reacted with $3900 \mu \mathrm{L}$ of working DPPHsolution (i.e., diluting the commercial DPPH solution in methanol to attain an absorbance of about $0.98 \pm 0.02$ at $517 \mathrm{~nm}$ ), and the mixture was let stand for 30 minutes in a dark reaction tube. The reducing ability of antioxidants towards DPPH could be determined by decreasing its absorbance at $515-528 \mathrm{~nm}$, in this case, measured at $517 \mathrm{~nm}$.

For ABTS, the assay was conducted based on the method, which referenced from Marc [17]. The radical cation $\left(\mathrm{ABTS}^{+} \bullet\right.$ ) was generated through the reaction between aqueous stock solutions of ABTS and $\mathrm{K}_{2} \mathrm{~S}_{2} \mathrm{O}_{8}$ to reach the final concentrations of $7.0 \mathrm{mmol} \mathrm{L}{ }^{-1}$ and $2.45 \mathrm{mmol}$ $\mathrm{L}^{-1}$, respectively, within the time period from 12 to $16 \mathrm{~h}$ in the dark (avoiding direct light) at the room temperature. Prior to use, the $\mathrm{ABTS}^{+} \cdot$ stock solution was diluted by the acetate buffer solution $\left.(\mathrm{pH}=4.5,0.3 \mathrm{~mol} \mathrm{~L})^{-1}\right)$ to obtain an absorbance of $0.74 \pm 0.03$ at $734 \mathrm{~nm}$. A diluted coffee sample volume of $200 \mu \mathrm{L}$ was mixed with $4000 \mu \mathrm{L}$ ABTS reagent. The mixture was 
shaken gently and protected from direct light for 7 minutes. The absorbance was measured at the wavelength of $734 \mathrm{~nm}$.

The FRAP and CUPRAC assays were employed to evaluate the reducing ability of coffee samples referenced from Pellegrini and Apak [18, 19], respectively, with some minor modifications. For FRAP, $100 \mu \mathrm{L}$ of the diluted sample solution was reacted with $3900 \mu \mathrm{L}$ of working FRAP solution (i.e., a mixture of $300 \mathrm{mmol} \mathrm{L}^{-1}$ sodium acetate-acetic acid buffer, 10 mmol L${ }^{-1}$ TPTZ solution, and $20 \mathrm{mmol} \mathrm{L}^{-1}$ ferric chloride solution at a volume ratio of 10:1:1). The mixture was let stand for 15 minutes before measuring at $593 \mathrm{~nm}$. For CUPRAC, $4.00 \mathrm{~mL}$ of the diluted coffee sample was mixed with $1.00 \mathrm{~mL}$ of $10^{-2} \mathrm{~mol} \mathrm{~L}^{-1} \mathrm{CuCl}_{2}, 1.00 \mathrm{~mL}$ of $7.5 \times 10^{-3} \mathrm{~mol} \mathrm{~L}^{-1}$ neocuproine in $\mathrm{EtOH}$, and $1.00 \mathrm{~mL}$ ammonium acetate buffer $(19.27 \mathrm{~g}$ ammonium acetate dissolved in $250 \mathrm{~mL}$ DIW, $\mathrm{pH}=7.0$ ). After 1 hour of incubation, the absorbance measurement was carried out at the wavelength of $450 \mathrm{~nm}$.

\subsection{Analytical method validation and application.}

All methods for determining TPCs and antioxidant capacities in coffee products were validated according to the instructions and requirements performed in Appendix F. AOAC (2016). The calibration curves were established based on the linear relationship $(y=a x+b)$ between the concentrations (mg GAE L ${ }^{-1}$ for TPCs and $\mu$ mol TE L $\mathrm{L}^{-1}$ for antioxidant capacities) and their absorbance values for quantification purposes. The limit of detection (LOD) was calculated as the concentration of analyte equals to threefold standard deviation of the blank absorbance divided by the calibration curve's slope value $\left(3 \mathrm{SD}_{\text {blank }} / \mathrm{a}\right)$, and the limit of quantification (LOQ) was calculated as $10 \mathrm{SD}_{\text {blank }} / \mathrm{a}$ [20]. The repeatability and reproducibility were assessed through the calculation of relative standard deviations for six replicates $(n=6)$ within one day $\left(\mathrm{RSD}_{\mathrm{r}}\right)$ and three separate days $\left(\mathrm{RSD}_{\mathrm{R}}\right)$ at a significant level of 0.05 . The method accuracy was evaluated from the recovery of spiked coffee samples.

The proposed analytical methods were applied for real coffee products to assess the variations of TPCs and antioxidant capacities among different coffee varieties of various roasting degrees. All the analytical data were carried out in triplicates $(n=3)$ and analyzed by Microsoft Office Excel 2016, then expressed as mean value \pm standard deviation (SD). The linear regression analysis was performed for potential correlation assessment among measurements (TPCs and antioxidant capacities).

\section{Results and Discussion}

\subsection{Analytical method performance for determining TPCs and antioxidant capacities in coffee.}

The analytical methods for determining TPCs, DPPH, ABTS, FRAP, and CUPRAC were evaluated according to Appendix F. AOAC (2016) [21] before application to real coffee samples. The parameters are presented in Table 2.

Table 2. Parameters for analytical method validation.

\begin{tabular}{l|l|l|l|l|l} 
Criteria & LOD-LOQ & Regression equation & RSD $_{\mathbf{r}}(\boldsymbol{\%})$ & RSD $_{\mathbf{R}}(\boldsymbol{\%})$ & Recoveries $(\%)$ \\
\hline TPCs & $2.92-8.84 *$ & $\begin{array}{l}\mathrm{y}=0.0103 \mathrm{x}-0.0274 \\
\mathrm{R}^{2}=0.9991\end{array}$ & 1.8 & 1.9 & $98.1-99.4$ \\
\hline DPPH & $23.21-70.23 * *$ & $\begin{array}{l}\mathrm{y}=0.0006 \mathrm{x}-0.0068 \\
\mathrm{R}^{2}=0.9995\end{array}$ & 1.8 & 1.8 & $97.5-100$ \\
\hline ABTS & $14.16-42.92 * *$ & $\begin{array}{l}\mathrm{y}=0.0009 \mathrm{x}-0.0097 \\
\mathrm{R}^{2}=0.9984\end{array}$ & 1.8 & 1.8 & $98.3-99.8$ \\
\hline FRAP & $27.06-82.01 * *$ & $\begin{array}{l}\mathrm{y}=0.0011 \mathrm{x}+0.0113 \\
\mathrm{R}^{2}=0.9982\end{array}$ & 1.4 & 1.5 & $97.8-101$ \\
\hline
\end{tabular}




\begin{tabular}{l|l|l|l|l|l}
\hline Criteria & LOD-LOQ & Regression equation & $\operatorname{RSD}_{\mathbf{r}}(\%)$ & $\operatorname{RSD}_{\mathbf{R}}(\%)$ & $\operatorname{Recoveries~}(\%)$ \\
\hline CUPRAC & $30.12-91.27 * *$ & $\begin{array}{l}\mathrm{y}=0.0020 \mathrm{x}-0.0958 \\
\mathrm{R}^{2}=0.9999 \\
(*) \mathrm{mg} \mathrm{GAE} \mathrm{L}^{-1} \text { and }(* *) \mu \mathrm{mol} \mathrm{TE} \mathrm{L} \mathrm{T}^{-1}\end{array}$ & 1.6 & $98.1-99.8$
\end{tabular}

The results in Table 2 indicated high squared correlation coefficient values of calibration curves for all analytical criteria, $0.995 \leq \mathrm{R}^{2} \leq 1$, revealing the goodness of linearity evidence (Appendix F. AOAC 2016) [21]. Relative standard deviation values for both intraday $\left(\% \mathrm{RSD}_{\mathrm{r}}\right)$ and inter-day $\left(\% \mathrm{RSD}_{\mathrm{R}}\right)$ were acceptable according to Appendix F. AOAC (2016) [21], lower than 5.3 and $8 \%$ for $\% \mathrm{RSD}_{\mathrm{r}}$ and $\% \mathrm{RSD}_{\mathrm{R}}$, respectively (analyte concentrations below $0.1 \%$ ). The obtained recoveries were always higher than $97 \%$ for all spiked samples, acceptable within the concentration ranges of $90-107 \%$ (100 ppm-0.1\%). The validated analytical method could be applied for the analysis of TPCs and TEACs in coffee samples.

\subsection{Variability in total polyphenol contents.}

The total polyphenol contents in ground coffee products are shown in Figure 1, with the highest and lowest values recorded in Robusta-Medium-1 (48.23 $\left.\pm 0.24 \mathrm{mg} \mathrm{GAE} \mathrm{g}^{-1}\right)$ and Arabica-Dark-2 $\left(27.1 \pm 2.4 \mathrm{mg} \mathrm{GAE} \mathrm{g}^{-1}\right)$, respectively.

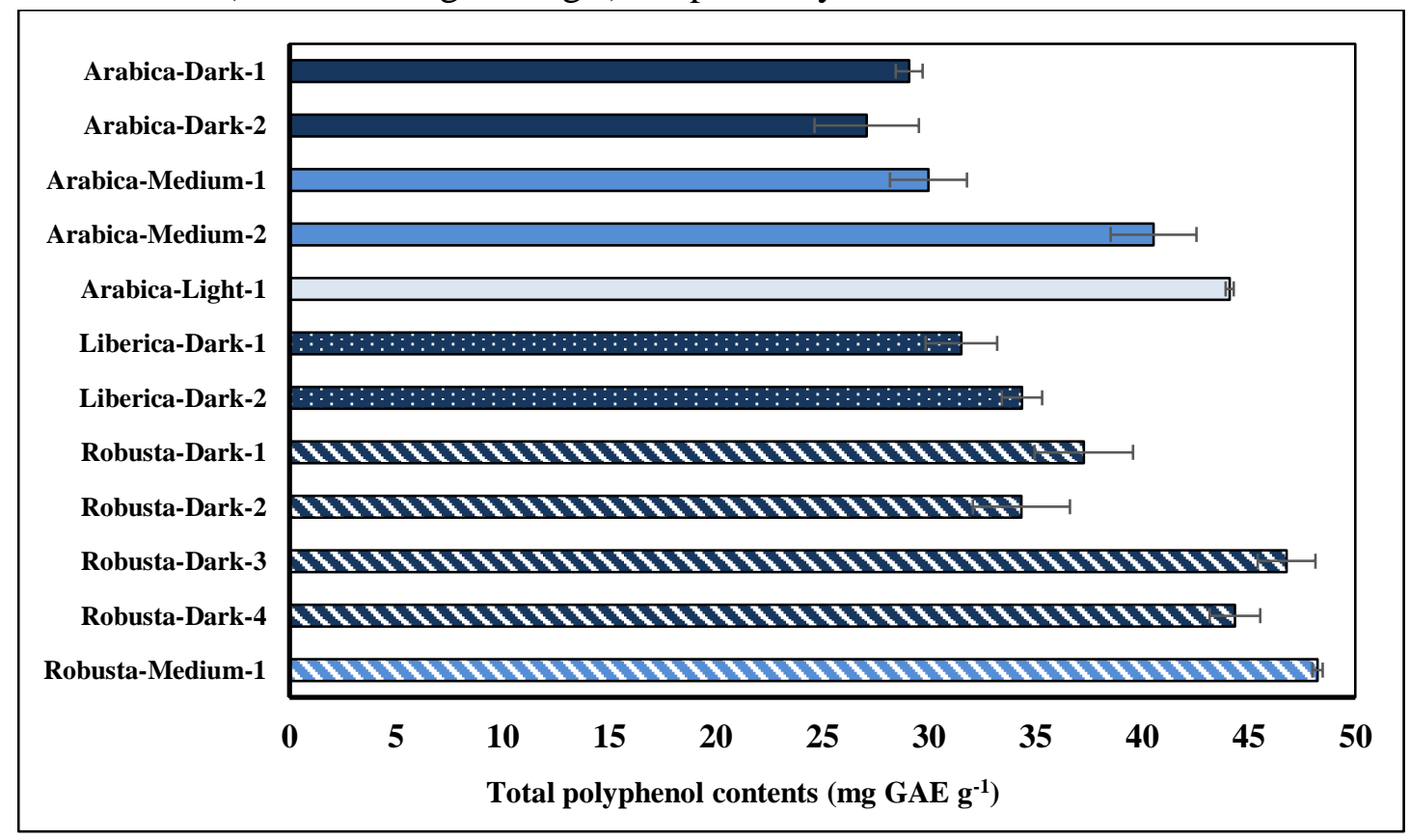

Figure 1. Total polyphenol contents in different coffee products.

Among three coffee types, the robusta presented their higher TPCs $(34.3 \pm 2.3$ to 48.23 $\left.\pm 0.24 \mathrm{mg} \mathrm{GAE}^{-1}\right)$ compared to the liberica $\left(31.5 \pm 1.7\right.$ to $\left.34.37 \pm 0.95 \mathrm{mg} \mathrm{GAE} \mathrm{g}^{-1}\right)$ and arabica products $\left(27.1 \pm 2.4\right.$ to $\left.44.11 \pm 0.19 \mathrm{mg} \mathrm{GAE} \mathrm{g}^{-1}\right)$. The higher TPCs of robusta than arabica were reported by Olechno et al. (2020) (0.534-7.112 vs. 0.504-6.832 $\mathrm{mg} \mathrm{GAE} \mathrm{g}^{-1}$ ) [22], but lower than our values due to their extraction in $100 \%$ water (i.e., compared to our study, the coffee was extracted in $70 \%$ methanol, leading to higher extraction percentage) and Perdani et al. (2019) (5.24-35.67 vs. 3.86-33.21 $\mathrm{mg} \mathrm{GAE} \mathrm{g}^{-1}$ ) [23]. Moreover, the roasting degrees contributed to the changes in TPCs in the same coffee type [24]. Apparently, the arabica exhibited the descending TPCs of light $\left(44.11 \pm 0.19 \mathrm{mg} \mathrm{GAE} \mathrm{g}^{-1}\right)$, medium (30.0 \pm 1.8 to 40.5 $\left.\pm 2.0 \mathrm{mg} \mathrm{GAE} \mathrm{g}^{-1}\right)$, and dark $\left(27.1 \pm 2.4\right.$ to $\left.20.07 \pm 0.63 \mathrm{mg} \mathrm{GAE} \mathrm{g}^{-1}\right)$ roasting degrees. A similar trend could be observed for the robusta coffee products, which showed the higher TPCs of medium ( $\left.48.23 \pm 0.24 \mathrm{mg} \mathrm{GAE} \mathrm{g}^{-1}\right)$ compared to dark $\left(34.3 \pm 2.3\right.$ to $44.4 \pm 1.2 \mathrm{mg} \mathrm{GAE} \mathrm{g}^{-}$ 
${ }^{1}$ ) roasting coffee products. The decrease in the concentrations of total polyphenol could be explained because the polyphenolic compounds were considered highly active and temperature-sensitive, so the roasting conditions at higher temperature led to the decomposition these polyphenols $[9,25,26]$.

\subsection{Variability in antioxidant capacities.}

We employed molecular absorption or UV-Vis spectrophotometry to determine the antioxidant activities by various chemical reaction mechanisms, including (2,2-diphenyl-1picryl-hydrazyl-hydrate) (DPPH) and 2,2'-azino-bis-3-ethylbenzthiazoline-6-sulphonic acid (ABTS) free radical scavenging assays; ferric reducing antioxidant power (FRAP) and cupric ion reducing antioxidant capacity (CUPRAC). The results are exhibited in Figure 2.

\begin{tabular}{|c|c|c|c|}
\hline $\begin{array}{r}\text { Arabica-Dark-1 } \\
\text { Arabica-Dark-2 } \\
\text { Arabica-Medium-1 } \\
\text { Arabica-Medium-2 } \\
\text { Arabica-Light-1 } \\
\text { Liberica-Dark-1 } \\
\text { Liberica-Dark-2 } \\
\text { Robusta-Dark-1 } \\
\text { Robusta-Dark-2 } \\
\text { Robusta-Dark-3 } \\
\text { Robusta-Dark-4 } \\
\text { Robusta-Medium-1 }\end{array}$ & 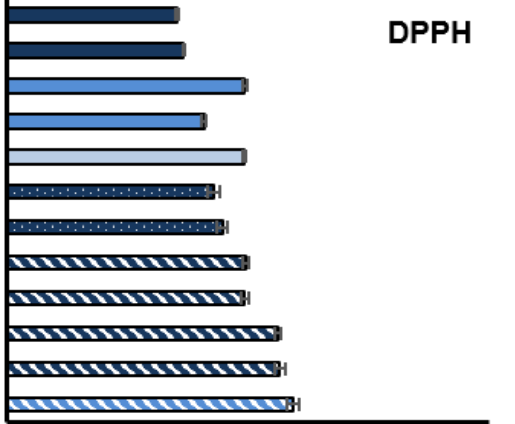 & $\begin{array}{r}\text { Arabica-Dark-1 } \\
\text { Arabica-Dark-2 } \\
\text { Arabica-Medium-1 } \\
\text { Arabica-Medium-2 } \\
\text { Arabica-Light-1 } \\
\text { Liberica-Dark-1 } \\
\text { Liberica-Dark-2 } \\
\text { Robusta-Dark-1 } \\
\text { Robusta-Dark-2 } \\
\text { Robusta-Dark-3 } \\
\text { Robusta-Dark-4 } \\
\text { Robusta-Medium-1 }\end{array}$ & \begin{tabular}{|l|} 
\\
\end{tabular} \\
\hline & 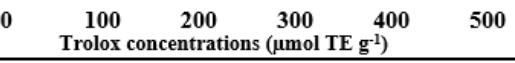 & & $\begin{array}{cccc}100 & 200 & 300 & 400 \\
\text { Trolox concentrations } & (\mu \mathrm{mol} & \mathrm{TE} & \left.\mathrm{g}^{-1}\right)\end{array}$ \\
\hline $\begin{array}{r}\text { Arabica-Dark-1 } \\
\text { Arabica-Dark-2 } \\
\text { Arabica-Medium-1 } \\
\text { Arabica-Medium-2 } \\
\text { Arabica-Light-1 } \\
\text { Liberica-Dark-1 } \\
\text { Liberica-Dark-2 } \\
\text { Robusta-Dark-1 } \\
\text { Robusta-Dark-2 } \\
\text { Robusta-Dark-3 } \\
\text { Robusta-Dark-4 } \\
\text { Robusta-Medium-1 }\end{array}$ & 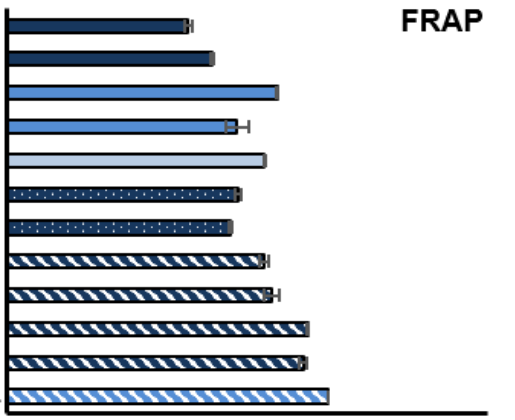 & $\begin{array}{r}\text { Arabica-Dark-1 } \\
\text { Arabica-Dark-2 } \\
\text { Arabica-Medium-1 } \\
\text { Arabica-Medium-2 } \\
\text { Arabica-Light-1 } \\
\text { Liberica-Dark-1 } \\
\text { Liberica-Dark-2 } \\
\text { Robusta-Dark-1 } \\
\text { Robusta-Dark-2 } \\
\text { Robusta-Dark-3 } \\
\text { Robusta-Dark-4 } \\
\text { Robusta-Medium-1 }\end{array}$ & 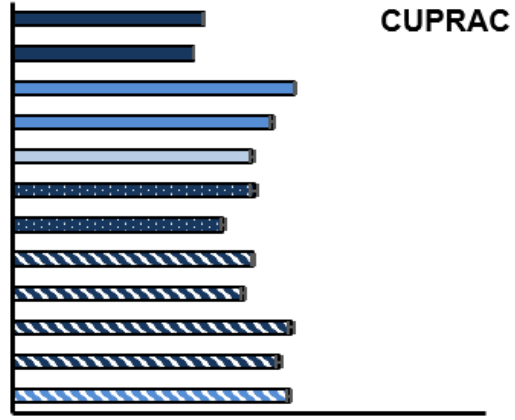 \\
\hline & $\begin{array}{cccc}100 & 200 & 300 & 400 \\
\text { Trolox concentrations } & (\mu \mathrm{mol} \\
(\mathrm{TE} & \left.\mathrm{g}^{-1}\right)\end{array}$ & & $\begin{array}{cccc}100 & 200 & 300 & 400 \\
\text { Trolox concentrations } & (\mu \mathrm{mol} & \mathbf{T E} & \left.\mathrm{g}^{-1}\right)\end{array}$ \\
\hline
\end{tabular}

Figure 2. Antioxidant capacities of different coffee products.

\subsubsection{DPPH and ABTS radical scavenging activity.}

The scavenging activity of the diphenyl-2-picrylhydrazyl (DPPH) radicals was considered among the initial steps to evaluate the antioxidant properties of ground coffee products and other sample matrices based on different chemical reaction mechanisms [27-30]. The scavenging activity of DPPH free radical determines and evaluates the antioxidant potential, which exhibits its effectiveness, prevention, interception, and repair mechanism against injury in biological systems. The DPPH existing in oxidized form performs a deep purple color in organic methanol solvent. When any compounds with antioxidant capacities were added to a DPPH reagent solution, the antioxidants would donate their electron to DPPH. This phenomenon reduces DPPH reagent happen, and in the reduced form, the DPPH color transforms from deep violet to yellow [15, 31, 32] (Figure 3). 


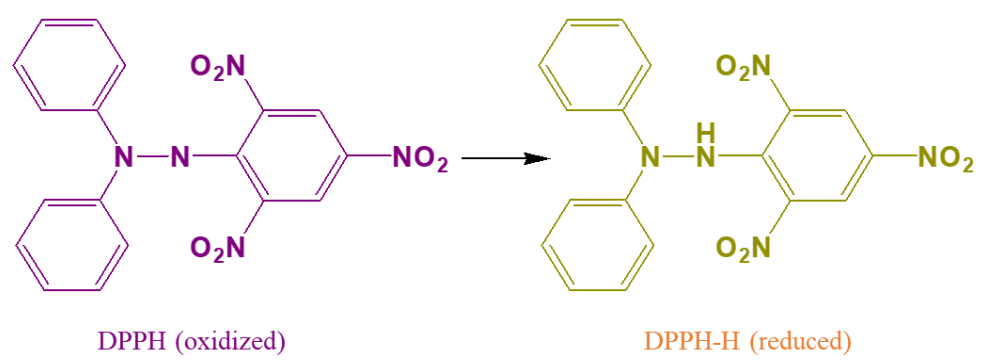

Figure 3. Formation of DPPH-H (reduced) from DPPH (oxidized).

As in the situation of TPCs, the robusta coffee products performed their higher DPPH values compared to the rest two types $\left(246.7 \pm 3.6\right.$ vs. $176.4 \pm 1.4$ to $\left.246.6 \pm 2.0 \mu \mathrm{mol} \mathrm{TE} \mathrm{g}^{-1}\right)$ (Figure 2), with the highest and lowest recorded in Robusta-Medium-1 (296.7 $\pm 6.7 \mu \mathrm{mol}$ TE $\left.\mathrm{g}^{-1}\right)$ and Arabica-Dark-1 (176.4 $\left.\pm 1.4 \mu \mathrm{mol} \mathrm{TE} \mathrm{g}^{-1}\right)$, respectively. As shown in Figure 2, the roasting degrees affected the DPPH values, in which dark roasting levels showed the lowest DPPH for both arabica (176.4-183.4 $\mu \mathrm{mol} \mathrm{TE} \mathrm{g}^{-1}$ ) and robusta (246.8-282.9 $\left.\mu \mathrm{mol} \mathrm{TE} \mathrm{g}^{-1}\right)$ coffee products. Moreover, the arabica products performed larger variations between dark and light modes than the robusta (variations of $69.4 \mathrm{vs} .49 .9 \mu \mathrm{mol} \mathrm{TE} \mathrm{g}^{-1}$ ) in spite of the lower DPPH values of arabica than those of robusta.

In the ABTS free radical method, ABTS can be oxidized by potassium persulfate or manganese dioxide. ABTS free radical absorbs in a wavelength of $743 \mathrm{~nm}$ (blue-green) due to the loss of one electron on the nitrogen atom of ABTS [17]. In the presence of trolox or an antioxidant capable of giving hydrogen, the nitrogen atoms quenched the hydrogen atom, yielding the solution decolorization [30, 32] (Figure 4).

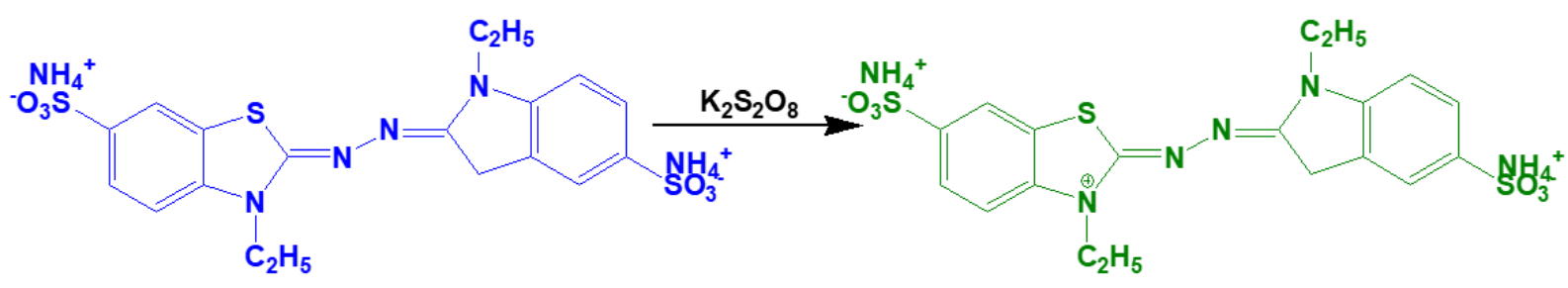

Figure 4. Formation of stable ABTS radical from ABTS with potassium persulfate.

The differences in ABTS radical scavenging activities among coffee products are shown in Figure 2, in which Robusta-Dark-3 and Arabica-Dark-1 exhibited their highest and lowest values of $477.4 \pm 7.1$ and $302.59 \pm 0.81 \mu \mathrm{mol} \mathrm{TE} \mathrm{g}^{-1}$, respectively. Similar to DPPH, the ABTS antioxidant capacities followed the descending order of robusta, liberica, and arabica. However, within one coffee type under different roasting degrees, the variations were not as much as DPPH, and the trend was distinctive from DPPH and TPCs. For the arabica products, the samples under medium roasting performed the highest ABTS antioxidant capacities $\left(398.9 \pm 3.8\right.$ and $428.26 \pm 0.93 \mu \mathrm{mol} \mathrm{TE} \mathrm{g}^{-1}$ for Arabica-Medium-2 and ArabicaMedium-1, respectively), while the Robusta coffee products exhibited the highest ABTS values in dark roasting (413.47 \pm 0.66 to $477.4 \pm 7.0 \mu \mathrm{mol} \mathrm{TE} \mathrm{g}^{-1}$ ) and smaller for medium roasting $\left(413.66 \pm 0.67 \mu \mathrm{mol} \mathrm{TE} \mathrm{g}^{-1}\right)$.

Comparing the results of antioxidant capacities derived from DPPH and ABTS, we could observe the higher values of ABTS than those of DPPH (302.6-477.4 vs. 176.4-296.7 $\mu \mathrm{mol} \mathrm{TE} \mathrm{g}^{-1}$ ). The antioxidant capacities of phenolic compounds depended on the number of hydroxyl groups in their chemical structure. Besides, the positions of $-\mathrm{OH}$ groups also influenced the antioxidant activity, in which -OH groups on the positions of 3' -, 4' -, 5'- in Bring of flavonoids would raise the antioxidant capacities. The samples contained dominant 
phenolic compounds with one hydroxyl group that performed lower antioxidant activity [3335]. The DPPH did not have the ability to react with the flavonoid compounds not containing any hydroxyl groups in B-ring as well as with aromatic acids having only one OH-group; whereas, the ABTS exhibited its low selectivity when reacting with $\mathrm{H}$-atom donors because it could have reactions with any hydroxylated aromatic chemical compounds independently on their real antioxidant activities [36, 37].

\subsubsection{Ferric and cupric reducing antioxidant power (FRAP and CUPRAC).}

The FRAP method was based on the reduction reaction of $\mathrm{Fe}^{3+}-\mathrm{TPTZ}(2,4,6$-tris $(2-$ pyridyl)-1,3,5-triazine) with antioxidant compounds forming $\mathrm{Fe}^{2+}-\mathrm{TPTZ}$. The binding of $\mathrm{Fe}^{2+}$ to the ligands creates a deeply intense navy blue color. The absorbance at $593 \mathrm{~nm}$ could be measured the examine the amount of iron reduced and correlated with the concentrations of antioxidants [18, 38] (Figure 5).

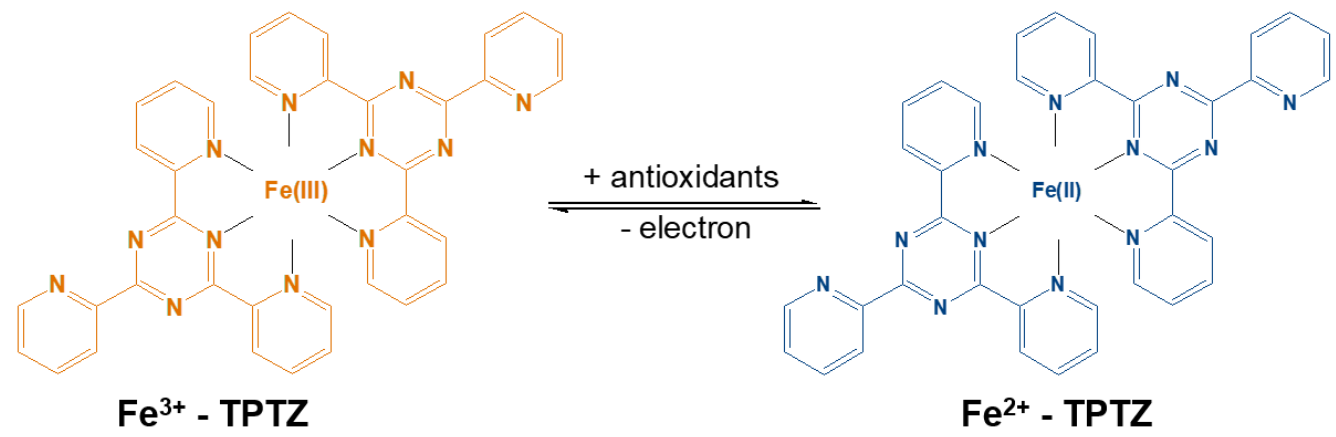

Figure 5. Formation of ( $\left.\mathrm{Fe}^{2+}-\mathrm{TPTZ}\right)$ complex from $\mathrm{Fe}^{3+}-\mathrm{TPTZ}$ by antioxidants.

The reducing power of the coffee products was determined and evaluated through both the FRAP and CUPRAC assays. The results of FRAP present in Figure 2 indicated the highest for Robusta-Medium-1 (334.18 $\left.\pm 0.03 \mu \mathrm{mol} \mathrm{TE} \mathrm{g}^{-1}\right)$ and the lowest for Arabica-Dark-1 (188.4 $\pm 4.2 \mu \mathrm{mol} \mathrm{TE} \mathrm{g}^{-1}$ ). Within the same roasting (dark), the robusta products showed the higher FRAP values than the liberica and arabica products $\left(267.6 \pm 4.1\right.$ to $334.18 \pm 0.03 \mu \mathrm{mol} \mathrm{TE} \mathrm{g^{- }}$ ${ }^{1}, 232.9 \pm 1.4$ to $240.6 \pm 2.8 \mu \mathrm{mol} \mathrm{TE} \mathrm{g}{ }^{-1}$, and $188.4 \pm 4.2$ to $281.16 \pm 0.87 \mu \mathrm{mol} \mathrm{TE} \mathrm{g}^{-1}$ for robusta, liberica, and arabica, respectively). However, unlike ABTS, medium and light roasting degrees exhibited higher FRAP values than dark roasting for arabica and robusta coffee products (Figure 2).

For the CUPRAC assay, the sample solution was mixed with $\mathrm{CuCl}_{2}$ and neocuproine (Nc) solutions, in which $\mathrm{Cu}(\mathrm{II})$ was reduced to $\mathrm{Cu}(\mathrm{I})$ through the action of electron-donating antioxidants $[19,30]$. After the chemical reaction, the absorbance was measured at $450 \mathrm{~nm}$ (Figure 6).
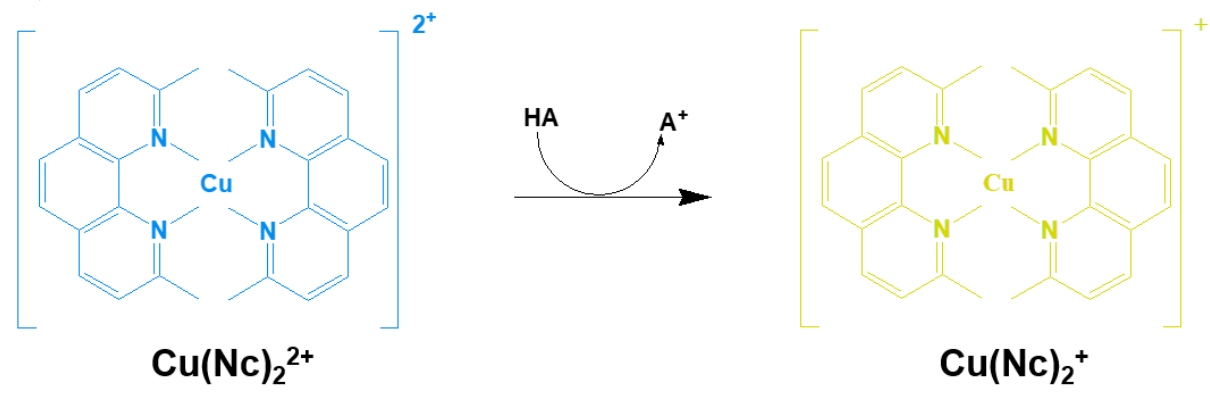

Figure 6. Formation of $\mathrm{Cu}(\mathrm{Nc})_{2}{ }^{+}$complex from $\mathrm{Cu}(\mathrm{Nc})_{2}{ }^{2+}$ by antioxidants. 
The results of CUPRAC among different coffee products are shown in Figure 2 for comparison. The arabica performed the higher CUPRAC than robusta, in which ArabicaMedium-1 reached the highest $\left(298.22 \pm 0.49 \mu \mathrm{mol} \mathrm{TE} \mathrm{g}^{-1}\right)$. However, the variations among the three types were not much, typically for robusta and liberica $(222.4 \pm 2.6$ vs. $255.4 \pm 3.5$ $\mu \mathrm{mol} \mathrm{TE} \mathrm{g}^{-1}$ ).

For most situations, the robusta showed the higher TPCs and TEACs, except for CUPRAC, compared to the rest two types of liberica and abrabica. The differences in their internal compositions could explain the higher TPCs and TEACs of the robusta products than the arabica. The coffee beans contain many chemical compounds with antioxidant capacities, mostly belonging to the hydroxycinnamic acid antioxidants (caffeic, chlorogenic, coumaric, ferulic, and sinapic acids) and others such as caffeine, nicotinic acid, trigonelline, cafestol, and kahweol. Among these compounds, chlorogenic acid is considered to play the most important role in the antioxidant capacities of coffee products. Then, chlorogenic acid varied remarkably between arabica (4.0-8.4\%) and robusta (7.0-14.4), contributing to the differences in their antioxidant behavior $[39,40]$.

Within the one coffee type, the medium roasting condition usually performed the highest TPCs and TEACs, while in a few situations, light or dark roasting showed the bigger TPCs and TEACs, but the variations between medium and light or dark modes were not much (Figure 10). The processing period, particularly the roasting, created many complicated chemical reactions that changed the coffee antioxidant capacities. During the processing periods, the temperature could decompose or polymerize the highly active compounds with high antioxidant capacities (e.g. phenolic acids). However, under the processing conditions rich in carbohydrates and proteins with the water shortage, the Maillard reactions could happen, forming several antioxidant compounds, mainly melanoidins [39-41].

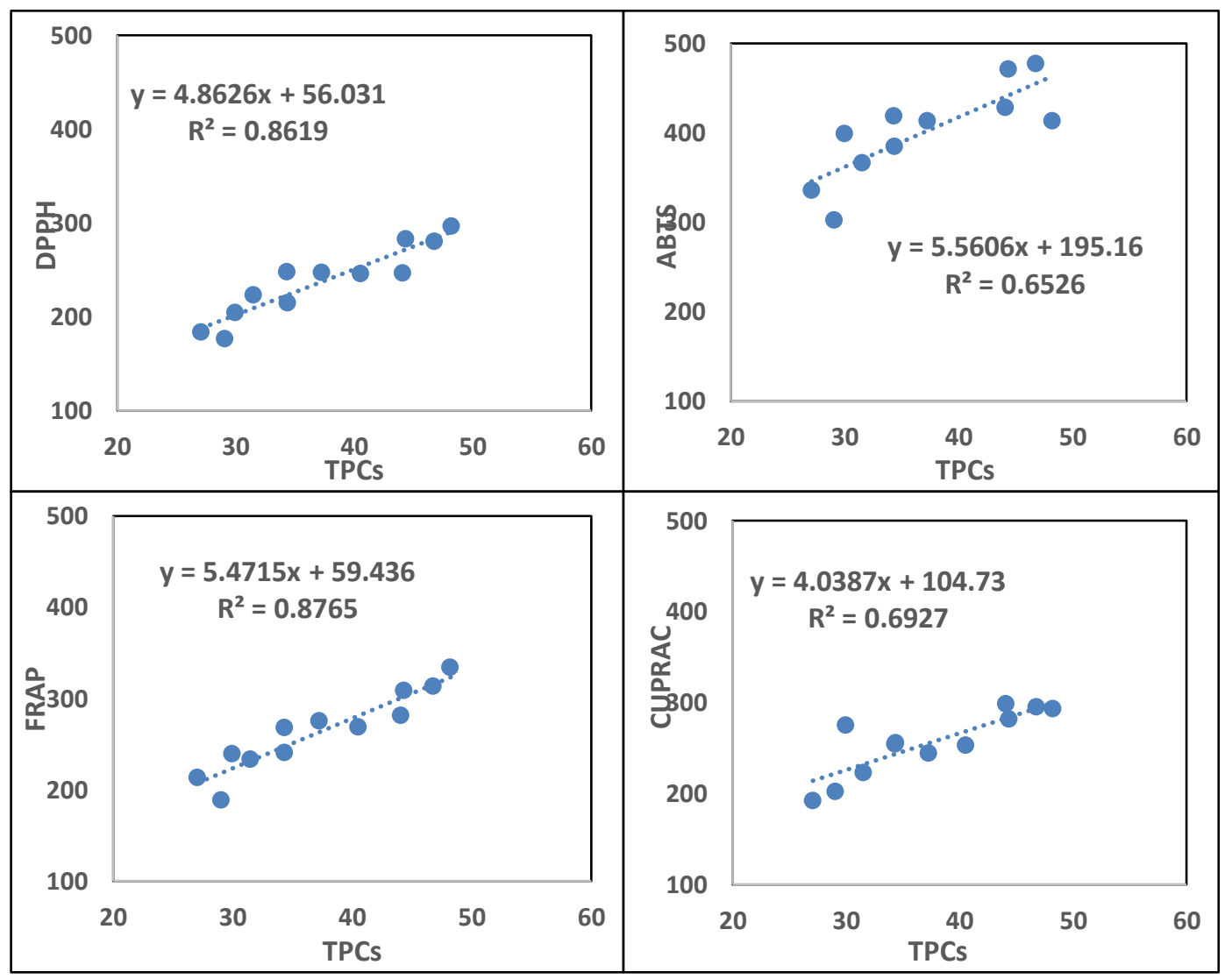

Figure 7. Correlation between TPCs and antioxidant capacities (DPPH, ABTS, FRAP, and CUPRAC). 
The melanoidins are among the main constituents of coffee brews (up to 25\% dried weight) and responsible for the antioxidant capacities [12, 42], leading to higher TPCs and TEACs for a medium roasting degree due to the balance between the degradation of phenolic compounds and the generation of new antioxidant compounds, in which the production of melanoidins performed a remarkable effect on the antioxidant capacities of roasted coffee products. The same observation was in agreement with the publications of del Castillo et al. (2002) [10], Nicoli et al. (1997) [43], and Opitz et al. (2014) [11]. Therefore, it could be said that during the roasting period of coffee beans, two major events affecting the antioxidant capacities were the degradation of low-molecular-weight phenolic compounds and the formation of Maillard reaction products (melanoidins) [40, 44, 45].

The correlations between analytical values of TPCs and antioxidant capacities, including DPPH, ABTS, FRAP, and CUPRAC of available coffee products, were performed in Figure 7.

As can be seen from Figure 7, there were strong correlations between total phenolic contents and antioxidant capacities (TPCs vs. DPPH, $\mathrm{R}^{2}=0.8619, \mathrm{p}<0.001$; TPCs vs. FRAP, $\mathrm{R}^{2}=0.8765, \mathrm{p}<0.001$; TPCs vs. CUPRAC, $\mathrm{R}^{2}=0.6927, \mathrm{p}<0.001$; and TPCs vs. ABTS, $\mathrm{R}^{2}$ $=0.6526, \mathrm{p}<0.001)$. Therefore, rich phenolic compounds played key roles in the potent antioxidant activities regarding free radical scavenging and reducing abilities. Strong correlation among these criteria were reported in various publications for coffee $[4,46,47]$, tea [48-50], Indian pulses and split pulses [51], Umbelliferae Salad Plants [52], and Maca [53].

\section{Conclusions}

This study demonstrated the variation among different coffee varieties for total polyphenol contents and antioxidant capacities as determined by four chemical reaction mechanisms (DPPH, ABTS, FRAP, and CUPRAC). The robusta coffee generally performed higher TPCs and TEACs than those of liberica and arabica. Besides, these values were also influenced by the roasting degrees during the processing period. The phenolic contents greatly contributed to the antioxidant properties due to high correlations recorded between TPCs and TEACs. The natural phenolic compounds present in coffee were partially destroyed or degraded by the roasting process, while other antioxidant compounds (e.g., melanoidins) might be formed, then it is possible to maintain or even increase the antioxidant activities. The medium roasting degree usually performed the highest TEACs due to the balance between the degradation of phenolic fraction and the formation of new antioxidants, mainly from the Maillard reaction. However, as the roasting intensity increased, the greater destruction of phenolics might not be compensated for by the formation of other compounds, leading to the lower TEACs recorded from dark roasting than medium and light roasting degrees. However, due to experiment time and conditions limitations, this study did not carry out roasting degrees for liberica coffee. Therefore, more samples should be collected to better compare and assess roasting influences on the TPCs and TEACs of different coffee varieties, also for correlation assessment among obtained analytical criteria.

\section{Funding}

This research received no external funding. 


\section{Acknowledgments}

The authors would like to express our grateful thanks and appreciation to Nguyen Tat Thanh University for the assistance and support during this study.

\section{Conflicts of Interest}

The authors declare no conflict of interest.

\section{References}

1. Xiao, F.; Xu, T.; Lu, B.; Liu, R. Guidelines for antioxidant assays for food components. Food Frontiers 2020 , 1, 60-69, https://doi.org/10.1002/fft2.10.

2. Huang, D.; Ou,B.; Prior, R. L. The chemistry behind antioxidant capacity assays. J. Agric. Food Chem. 2005, 53, 1841-1856, https://doi.org/10.1021/jf030723c.

3. Cleverdon, R.; Elhalaby, Y.; McAlpine, M. D.; Gittings, W.; Ward, W. E. Total polyphenol content and antioxidant capacity of tea bags: comparison of black, green, red rooibos, chamomile and peppermint over different steep times. Beverages 2018, 4, 15, https://doi.org/10.3390/beverages4010015.

4. Vignoli, J. A.; Viegas, M. C.; Bassoli, D. G.; de Toledo Benassi, M. Roasting process affects differently the bioactive compounds and the antioxidant activity of arabica and robusta coffees. Int. Food Res. J. 2014, 61, 279-285, https://doi.org/10.1016/j.foodres.2013.06.006.

5. Daglia, M.; Papetti, A.; Gregotti, C.; Bertè, F.; Gazzani, G. In vitro antioxidant and ex vivo protective activities of green and roasted coffee. J. Agric. Food Chem. 2000, 48, 1449-1454, https://doi.org/10.1021/jf990510g.

6. Minamisawa, M.; Yoshida, S.; Takai, N. Determination of biologically active substances in roasted coffees using a diode-array HPLC system. Anal. Sci. 2004, 20, 325-328, https://doi.org/10.2116/analsci.20.325.

7. Manach, C.; Scalbert, A.; Morand, C.; Rémésy, C.; Jiménez, L. Polyphenols: food sources and bioavailability. Am. J. Clin. Nutr. 2004, 79, 727-747, https://doi.org/10.1093/ajen/79.5.727.

8. Wang, H.-Y.; Qian, H.; Yao, W.-R. Melanoidins produced by the Maillard reaction: Structure and biological activity. Food Chem. 2011, 128, 573-584, https://doi.org/10.1016/j.foodchem.2011.03.075.

9. Asfaw, G.; Tefera, M. Total polyphenol content of green, roasted and cooked Harar and Yirgacheffee Coffee, Ethiopia. JASEM 2020, 24, 187-192, https://doi.org/10.4314/jasem.v24i1.27.

10. del Castillo, M. D.; Ames, J. M.; Gordon, M. H. Effect of roasting on the antioxidant activity of coffee brews. J. Agric. Food Chem. 2002, 50, 3698-3703, https://doi.org/10.1021/jf011702q.

11. Opitz, S. E.; Smrke, S.; Goodman, B. A.; Keller, M.; Schenker, S.; Yeretzian, C. Antioxidant generation during coffee roasting: A comparison and interpretation from three complementary assays. Foods 2014, 3, 586-604, https://doi.org/10.3390/foods3040586.

12. Delgado-Andrade, C.; Morales, F. J. Unraveling the contribution of melanoidins to the antioxidant activity of coffee brews. J. Agric. Food Chem. 2005, 53, 1403-1407, https://doi.org/10.1021/jf048500p.

13. Andriot, I.; Le Quéré, J.-L.; Guichard, E. Interactions between coffee melanoidins and flavour compounds: impact of freeze-drying (method and time) and roasting degree of coffee on melanoidins retention capacity. Food Chem. 2004, 85, 289-294, https://doi.org/10.1016/j.foodchem.2003.07.007.

14. ISO 14502-1: Determination of substances characteristic of green and black tea-Part 1: Content of total polyphenols in tea-Colorimetric method using Folin-Ciocalteu reagent, 2005.

15. Brand-Williams, W.; Cuvelier, M.-E.; Berset, C. Use of a free radical method to evaluate antioxidant activity. LWT-Food science and Technology 1995, 28, 25-30, https://doi.org/10.1016/S0023-6438(95)80008-5.

16. Sánchez-Moreno, C. Methods used to evaluate the free radical scavenging activity in foods and biological systems. Food Sci. Technol. 2002, 8, 121-137, https://doi.org/10.1106/108201302026770.

17. Marc, F.; Davin, A.; Deglène-Benbrahim, L.; Ferrand, C.; Baccaunaud, M.; Fritsch, P. Studies of several analytical methods for antioxidant potential evaluation in food. Medecine Sciences: $M / S$ 2004, 20, 458-463, http://doi.org/10.1051/medsci/2004204458.

18. Pellegrini, N.; Serafini, M.; Colombi, B.; Del Rio, D.; Salvatore, S.; Bianchi, M. Total antioxidant capacity of plant foods, beverages and oils consumed in Italy assessed by three different in vitro assays. Nutr. J. 2003, 133, 2812-2819, https://doi.org/10.1093/jn/133.9.2812.

19. Apak, R.; Güçlü, K.; Özyürek, M.; Karademir, S. E. Novel total antioxidant capacity index for dietary polyphenols and vitamins $\mathrm{C}$ and $\mathrm{E}$, using their cupric ion reducing capability in the presence of neocuproine: CUPRAC method. J. Agric. Food Chem. 2004, 52, 7970-7981, https://doi.org/10.1021/jf048741x.

20. Inczédy, J.; Lengyel, T.; Ure, A. M.; Gelencsér, A.; Hulanicki, A. Compendium of analytical nomenclature. The Orange Book, 3rd ed.; Hoboken: Blackwell Science, 1998, https://doi.org/10.1016/c2013-0-02923-4.

21. Appendix F. AOAC: Guidelines for Standard Method Performance Requirements, 2016. 
22. Olechno, E.; Puścion-Jakubik, A.; Markiewicz-Żukowska, R.; Socha, K. Impact of Brewing Methods on Total Phenolic Content (TPC) in Various Types of Coffee. Molecules 2020, 25, https://doi.org/10.3390/molecules25225274.

23. Perdani, C.; Pranowo, D.; Qonitatilah Total phenols content of green coffee (Coffea arabica and Coffea canephora) in East Java. OP Conf. Ser. Earth Environ. Sci. 2019, 012093, http://doi.org/10.1088/17551315/230/1/012093.

24. Várady, M.; Hrušková, T.; Popelka, P. Effect of preparation method and roasting temperature on total polyphenol content in coffee beverages. Czech J. Food Sci. 2020, 38, 417-421, https://doi.org/10.17221/122/2020-CJFS.

25. Katsube, T.; Tsurunaga, Y.; Sugiyama, M.; Furuno, T.; Yamasaki, Y. Effect of air-drying temperature on antioxidant capacity and stability of polyphenolic compounds in mulberry (Morus alba L.) leaves. Food Chem. 2009, 113, 964-969, https://doi.org/10.1016/j.foodchem.2008.08.041.

26. Larrauri, J. A.; Rupérez, P.; Saura-Calixto, F. Effect of drying temperature on the stability of polyphenols and antioxidant activity of red grape pomace peels. J. Agric. Food Chem. 1997, 45, 1390-1393, https://doi.org/10.1021/jf960282f.

27. Liang, N.; Kitts, D. Antioxidant Property of Coffee Components: Assessment of Methods that Define Mechanisms of Action. Molecules (Basel, Switzerland) 2014, 19, 19180-19208, https://doi.org/10.3390/molecules191119180.

28. Ziemlewska, A.; Zagórska-Dziok, M.; Nizioł-Łukaszewska, Z. Assessment of cytotoxicity and antioxidant properties of berry leaves as by-products with potential application in cosmetic and pharmaceutical products. Sci. Rep. 2021, 11, 3240, https://doi.org/10.1038/s41598-021-82207-2.

29. Zhang, Q.; Yang, W.; Liu, J.; Liu, H.; Lv, Z.; Zhang, C.; Chen, D.; Jiao, Z. Identification of Six Flavonoids as Novel Cellular Antioxidants and Their Structure-Activity Relationship. Oxid. Med. Cell. Longev. 2020, 2020, 4150897, https://doi.org/10.1155/2020/4150897.

30. Munteanu, I. G.; Apetrei, C. Analytical Methods Used in Determining Antioxidant Activity: A Review. Int. J. Mol. Sci. 2021, 22, 3380, https://doi.org/10.3390/ijms22073380.

31. Mishra, K.; Ojha, H.; Chaudhury, N. K. Estimation of antiradical properties of antioxidants using DPPH assay: A critical review and results. Food Chem. 2012, 130, 1036-1043, https://doi.org/10.1016/j.foodchem.2011.07.127.

32. Abdullahi, A. D.; Kodchasee, P.; Unban, K.; Pattananandecha, T.; Saenjum, C.; Kanpiengjai, A.; Shetty, K.; Khanongnuch, C. Comparison of Phenolic Contents and Scavenging Activities of Miang Extracts Derived from Filamentous and Non-Filamentous Fungi-Based Fermentation Processes. Antioxidants 2021, 10, 1144, https://doi.org/10.3390/antiox10071144.

33. Rice-evans, C. A.; Miller, N. J.; Bolwell, P. G.; Bramley, P. M.; Pridham, J. B. The relative antioxidant activities of plant-derived polyphenolic flavonoids. Free Radic. Res. 1995, 22, 375-383, https://doi.org/10.3109/10715769509145649.

34. Heim, K. E.; Tagliaferro, A. R.; Bobilya, D. J. Flavonoid antioxidants: chemistry, metabolism and structureactivity relationships. J. Nutr. Biochem. 2002, 13, 572-584, https://doi.org/10.1016/S0955-2863(02)00208-5.

35. Kopjar, M.; Tadić, M.; Piližota, V. Phenol content and antioxidant activity of green, yellow and black tea leaves. Chem. biol. technol. 2015, 2, 1-6, https://doi.org/10.1186/s40538-014-0028-7.

36. Campos, A.; Lissi, E. Kinetics of the reaction between 2, 2'-azinobis (3-ethylbenzothiazoline-6-sulfonic acid (ABTS) derived radical cations and phenols. Int. J. Chem. Kinet. 1997, 29, 219-224, https://doi.org/10.1002/(SICI)1097-4601(1997)29:3<219::AID-KIN9>3.0.CO;2-X.

37. Arts, M. J.; Dallinga, J. S.; Voss, H.-P.; Haenen, G. R.; Bast, A. A critical appraisal of the use of the antioxidant capacity (TEAC) assay in defining optimal antioxidant structures. Food Chem. 2003, 80, 409-414, https://doi.org/10.1016/S0308-8146(02)00468-5.

38. Li, D.; Li, B.; Ma, Y.; Sun, X.; Lin, Y.; Meng, X. Polyphenols, anthocyanins, and flavonoids contents and the antioxidant capacity of various cultivars of highbush and half-high blueberries. J. Food Compos. Anal. 2017, 62, 84-93, https://doi.org/10.1016/j.jfca.2017.03.006.

39. Farah, A.; Donangelo, C. M. Phenolic compounds in coffee. Braz. J. Plant Physiol. 2006, 18, 23-36, https://doi.org/10.1590/S1677-04202006000100003.

40. Farah, A.; de Paulis, T.; Trugo, L. C.; Martin, P. R. Effect of roasting on the formation of chlorogenic acid lactones in coffee. J. Agric. Food Chem. 2005, 53, 1505-1513, https://doi.org/10.1021/jf048701t.

41. Liu, X.; Xia, B.; Hu, L. T.; Ni, Z. J.; Thakur, K.; Wei, Z. J. Maillard conjugates and their potential in food and nutritional industries: A review. Food Frontiers 2020, 1, 382-397, https://doi.org/10.1002/fft2.43.

42. Muñoz, A. E.; Hernández, S. S.; Tolosa, A. R.; Burillo, S. P.; Herrera, M. O. Evaluation of differences in the antioxidant capacity and phenolic compounds of green and roasted coffee and their relationship with sensory properties. LWT 2020, 128, 109457, https://doi.org/10.1016/j.lwt.2020.109457.

43. Nicoli, M.; Anese, M.; Manzocco, L.; Lerici, C. Antioxidant properties of coffee brews in relation to the roasting degree. LWT-Food Science and Technology 1997, 30, 292-297, https://doi.org/10.1006/fstl.1996.0181. 
44. Komes, D.; Bušić, A. Antioxidants in coffee. In processing and impact on antioxidants in beverages. 1st ed: Victor Preedy. King's College London, UK 2014, 25-32, https://doi.org/10.1016/B978-0-12-404738-9.000039.

45. Iriondo-DeHond, A.; Elizondo, A. S.; Iriondo-DeHond, M.; Ríos, M. B.; Mufari, R.; Mendiola, J. A.; Ibañez, E.; Dolores del Castillo, M. Assessment of Healthy and Harmful Maillard Reaction Products in a Novel Coffee Cascara Beverage: Melanoidins and Acrylamide. Foods 2020, 9, 620, https://doi.org/10.3390/foods9050620.

46. Tran, T. M. K.; Kirkman, T.; Nguyen, M.; Van Vuong, Q. Effects of drying on physical properties, phenolic compounds and antioxidant capacity of Robusta wet coffee pulp (Coffea canephora). Heliyon 2020, 6, e04498, https://doi.org/10.1016/j.heliyon.2020.e04498.

47. Pérez-Hernández, L. M.; Chávez-Quiroz, K.; Medina-Juárez, L. Á.; Gámez Meza, N. Phenolic characterization, melanoidins, and antioxidant activity of some commercial coffees from Coffea arabica and Coffea canephora. J. Mex. Chem. Soc. 2012, 56, 430-435, http://www.scielo.org.mx/scielo.php?pid=S1870249X2012000400012\&script=sci_arttext\&tlng=en.

48. Zhao, C.-N.; Tang, G.-Y. Cao, S.-Y.; Xu, X.-Y.; Gan, R.-Y.; Liu, Q.; Mao, Q.-Q.; Shang, A.; Li, H.-B. Phenolic profiles and antioxidant activities of 30 tea infusions from green, black, oolong, white, yellow and dark teas. Antioxidants 2019, 8, 215, https://doi.org/10.3390/antiox8070215.

49. Oboh, H.; Omoregie, I. Total phenolics and antioxidant capacity of some Nigerian beverages. Nig. J. Basic Appl. Sci. 2011, 19, https://doi.org/10.4314/njbas.v19i1.69346.

50. Jayasekera, S.; Molan, A. L.; Garg, M.; Moughan, P. J. Variation in antioxidant potential and total polyphenol content of fresh and fully-fermented Sri Lankan tea. Food Chem. 2011, 125, 536-541, https://doi.org/10.1016/j.foodchem.2010.09.045.

51. Parikh, B.; Patel, V. H. Total phenolic content and total antioxidant capacity of common Indian pulses and split pulses, J. Food Sci. Technol. 2018, 55, 1499-1507, https://doi.org/10.1007/s13197-018-3066-5.

52. Kim, J.-S.; Lee, J.-H. Correlation between solid content and antioxidant activities in Umbelliferae salad plants. Prev Nutr Food Sci. 2020, 25, 84, https://doi.org/10.3746/pnf.2020.25.1.84.

53. Gan, J.; Feng, Y.; He, Z.; Li, X.; Zhang, H. Correlations between Antioxidant Activity and Alkaloids and Phenols of Maca (Lepidium meyenii). J. Food Qual. 2017, 2017, 3185945, https://doi.org/10.1155/2017/3185945. 